\title{
Effects of the distribution density of a biomass combined heat and power plant network on heat utilisation efficiency in village-town systems
}

\author{
Zhang Yifei ${ }^{\mathrm{a}^{*}}$, Kang Jian ${ }^{\mathrm{b}, \mathrm{a}}$ \\ ${ }^{a}$ School of Architecture, Harbin Institute of Technology 150001, China, 29598757@qq.com \\ ${ }^{b}$ School of Architecture, University of Sheffield, Western Bank, Sheffield S10 2TN, United \\ Kingdom \\ * Corresponding author
}

Funding: This work was supported by the Natural Science Foundation of China [grant number 51578175]; and the Harbin Science and Technology Innovative Talent Project [grant number 2015RQQXJ066]

\begin{abstract}
The building of biomass combined heat and power (CHP) plants is an effective means of developing biomass energy because they can satisfy demands for winter heating and electricity consumption. The purpose of this study was to analyse the effect of the distribution density of a biomass CHP plant network on heat utilisation efficiency in a village-town system. The distribution density is determined based on the heat transmission threshold, and the heat utilisation efficiency is determined based on the heat demand distribution, heat output efficiency, and heat transmission loss. The objective of this study was to ascertain the optimal value for the heat transmission threshold using a multi-scheme comparison based on an analysis of these factors. To this end, a model of a biomass CHP plant network was built using geographic information system tools to simulate and generate three planning schemes with different heat transmission thresholds $(6,8$, and $10 \mathrm{~km})$ according to the heat demand distribution. The heat utilisation efficiencies of these planning schemes were then compared by calculating the gross power, heat output efficiency, and heat transmission loss of the biomass CHP plant for each scenario. This multi-scheme comparison yielded the following results: when the heat transmission threshold was low, the distribution density of the biomass CHP plant network was high and the biomass CHP plants tended to be relatively small. In contrast, when the heat transmission threshold was high, the distribution density of the network was low and the biomass CHP plants tended to be relatively large. When the heat transmission threshold was $8 \mathrm{~km}$, the distribution density of the biomass CHP plant network was optimised for efficient heat utilisation. To promote the development of renewable energy sources, a planning scheme for a biomass CHP plant network that maximises heat utilisation efficiency can be obtained using the optimal heat transmission threshold and the nonlinearity coefficient for local roads.
\end{abstract}

Key words: Biomass CHP plant; Distribution density; Heat utilisation efficiency; Village-town system; Fujin

2017 Journal of Environmental Management

Date Received: 23 April 2017 Date Accepted: 8 July 2017

Publish online: 14-Jul-2017

\section{Introduction}

Biomass is a unique renewable energy source because it can be stored easily[1]. For this reason, researchers worldwide have aimed to develop more efficient ways to utilise biomass energy, with the goal of reducing the consumption of non-renewable energy sources and the associated environmental pollution[2]. One of the objectives of this research is to improve the utilisation efficiency of biomass energy in the context of village-town system planning.

Scarlat et al.[3] and Peter[4] concluded that the energy conversion efficiencies of straw-fired 
cogeneration and liquid fuel technologies are approximately $20-40 \%$ and $40-50 \%$, respectively. Guo et al.[5] argued that liquid fuel production is inefficient at low temperatures, and straw-fired cogeneration technology has become the first choice to achieve winter heating goals in cold regions. Scarlat et al.[6] and Göran[7] compared the energy utilisation efficiencies of straw-fired cogeneration technology and solid fuel production, and found that the energy utilisation efficiencies of these two methods differed slightly. As the production cost of solid fuel is relatively high, it is more economical to build biomass combined heat and power (CHP) plants using straw-fired cogeneration technology. Based on a combined study of landscape and energy planning, Thomas et al.[8] presented a method for predicting the gross power of biomass power plants according to the heat demand distribution, which involves analysing the population distribution of villages and towns. Xun et al.[9] used geographic information system (GIS) tools to analyse transportation costs for a biomass carrier from the perspective of village-town planning, and determined the economically optimal distribution density of biomass power plants. However, since the biomass CHP power plants in this model cannot meet winter heating goals, this model cannot be applied to cold regions. Dornburg and Faaij[10] suggested that the gross power of a biomass CHP plant is directly proportional to the energy conversion efficiency; the energy conversion efficiency reached $35 \%$ when the gross power of a biomass CHP plant reached 350 MWh. However, they did not consider the relationship between heat transmission loss and heat transmission distance. An investigation by $\mathrm{Lu}$ and $\mathrm{Xi}[11]$ into the relationship between heat transmission loss and heat pipe length from a town planning perspective showed that the heat loss ratio of a heating network was directly proportional to the heat transmission distance when the latter was limited to $20 \mathrm{~km}$.

These results illustrate that, based on development costs and heat output efficiency, building biomass CHP plants is an efficient way to develop biomass energy in village-town systems in cold regions. In addition, research into the heat demand distribution and heat transmission loss shows that the distribution density of biomass CHP plants affects construction costs. Based on these results, this study addresses the following question: can the distribution density of a biomass CHP plant network affect heat utilisation efficiency? This question involves investigating the ecological and economic concerns of village-town systems, a topic which has not previously been studied in depth.

The relationship between the distribution density of biomass CHP plants and their heat energy utilisation efficiency is not well studied, so investigating this relationship is the goal of the research presented here. Biomass CHP technology analyses involve heat utilisation efficiency, electricity utilisation efficiency, and many other factors, but this study focused on analysing heat utilisation efficiency because this is crucial to the energy saving required for winter heating in village-town systems in cold regions. Therefore, the purpose of this study was to evaluate the effect of the distribution density of a biomass CHP plant network on heat utilisation efficiency from the perspective of village-town system planning. Since heat utilisation efficiency is determined by the heat demand distribution, heat output efficiency, and heat transmission loss, these factors form the focus of this research. Based on theoretical models, GIS tools were used to perform overlay or network analyses of factors including the village-town distribution, population density, and road networks. Several different biomass CHP plant network planning schemes with various heat transmission threshold values (between 6-10 km) were simulated and generated, and a multi-scheme comparison was conducted to determine the optimal heat transmission threshold for maximising the heat utilisation efficiency. Studying this topic using GIS tools, for a series of simulation analyses with data that are readily available from local governments, represents a considerable cost saving compared to studies that use expensive remote sensing (RS) data or collect data from field surveys.

\section{Methods: biomass CHP plant network model and analysis of a typical case}

The heat transmission loss of a heating network increases as the transmission distance increases. Therefore, there is a threshold for the transmission distance from a biomass CHP plant to the end user: this distance cannot be increased indefinitely. This threshold differs depending on the country because of variations in municipal planning standards. The heat transmission threshold 
was the most important research target in this study.

\subsection{Range of heat transmission threshold values}

Due to its close relationship with heat transmission loss, heat transmission distance should be considered when establishing a biomass CHP plant network; its value can affect the service area and construction costs of biomass CHP plants[12-17]. According to conventional heating network design specifications in China, the optimal range of the heat transmission distance from plant to end user is $6-8 \mathrm{~km}$, and the maximum value is $10 \mathrm{~km}[18]$. Thomas et al. ${ }^{[8]}$ engaged 21 experts to evaluate a series of threshold values in terms of energy transmission, and the results demonstrated that the maximum heat transmission distance should be $10 \mathrm{~km}$. Although these results broadly agree, a further question arises: given the heat transmission distance range of $6-10 \mathrm{~km}$, what value within this range optimizes the heat utilization efficiency of a biomass CHP plant network? To answer this question, this study investigated the optimal value for the heat transmission threshold through a series of quantitative analyses. Owing to extremely high road construction costs, it is economical to build biomass CHP plants and install a heating network using existing roads, bearing in mind the required range for the heat transmission threshold.

\subsection{Basic and improved model forms}

The relationship between the locations of the biomass CHP plants and the radii of villages and towns can be deduced based on the heat transmission threshold $(T)$. Because the roads connecting villages and towns tend to form irregularly shaped networks, a road nonlinearity coefficient $[19](N)$ was incorporated, and the average service radius of the biomass CHP plants was set as $T / N$. Here, it was assumed that all the biomass CHP plants were regularly distributed on a plain; future research will investigate complex mountainous terrains. It is well known that a cellular structure is the best topological structure to cover a two-dimensional plane, so this structure was used as the basis of the biomass CHP plant network in this model, as shown in Figure 1. According to the known angles and side lengths of the equilateral triangles, the straight-line distance between two biomass CHP plants can be calculated as $T / N .2 \cot \left(30^{\circ}\right)$.

Various zigzag forms exist in real road networks; therefore, the average service radius $(T / N)$ in the above model will vary within a certain range, and the degree of variation can be determined based on the distribution density of the villages and towns[20].

In addition to the heat transmission threshold, the distribution status and populations of the villages and towns can affect the form of the biomass CHP plant network.

The distribution of villages and towns was the most crucial factor in estimating the heat demand distribution. If no villages or towns exist in a certain region, it is economical to remove all biomass CHP plants in this region from the regularly spaced network. The borders of the biomass CHP plant service areas adjacent to such a region transform from a hexagonal to a circular form. If the distribution density of villages and towns is relatively low in a certain region, the construction costs of a regularly

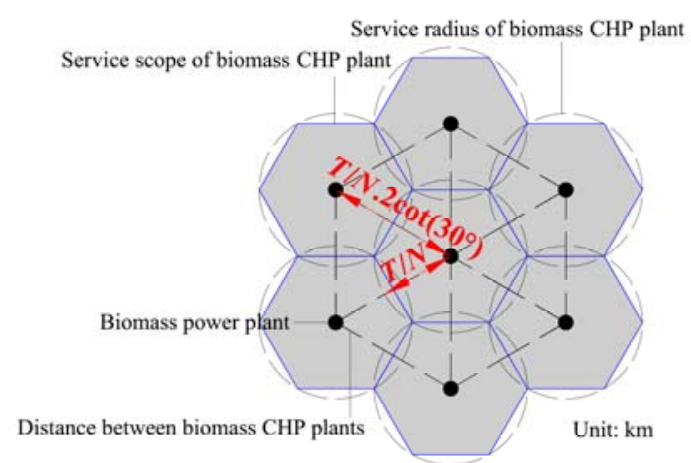

Fig. 1 Basic form of a biomass CHP plant network Service scope of biomass CHP plant Service radius of biomass CHP plant

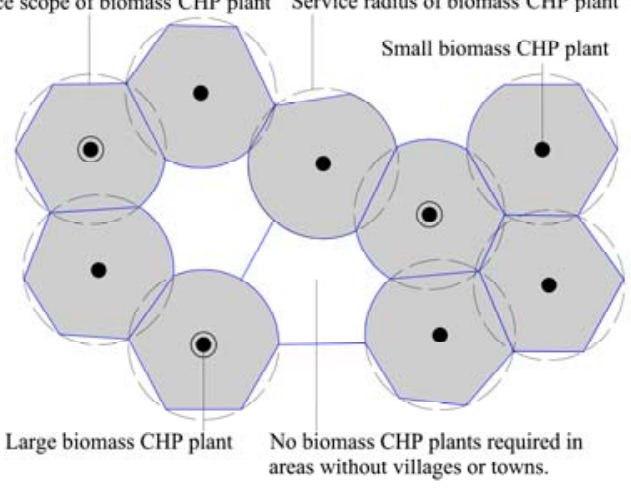

Fig. 2 Improved form of a biomass CHP plant network 
distributed biomass CHP plant network would be excessively high. In this case, it is economical to adjust the positions of some of the plants so that the resulting irregularly distributed network, with fewer biomass CHP plants, can serve the same number of villages and towns. When the distribution density of villages and towns is relatively high, the service area borders of the biomass CHP plants tend to form hexagonal shapes, whereas they tend to be circular when the distribution density of villages and towns is relatively low. Based on these rules, an improved form can be obtained for the biomass CHP plant network, as shown in Figure 2.

The populations of villages and towns are crucial factors in estimating the distribution of heat demand. The gross power of a given biomass CHP plant can be calculated based on the population it serves, and the entire network includes plants with different gross power requirements because the heat demand distribution across most regions is irregular (Figure 2).

The theoretical model discussed above provides the basic form of a biomass CHP plant network and the related rules for adaptation of this model; however, the inclusion of other renewable energy sources (RES) is usually required in practice. Based on the theoretical model, a detailed quantitative analysis of a typical case performed using GIS tools is required to determine the optimal value of $T$ to improve heat utilisation efficiency.

\subsection{Typical case analysis}

Based on the series of rules for the theoretical model described above, the selected village-town system should be an agricultural area located on a plain, and a typical case was chosen based on these conditions. Heilongiiang Province has the highest agricultural output of any province in China[21], is located in a sub-frigid climate zone, and has a biomass potential of 90,346,000 tonnes of standard coal; agricultural and forest biomass account for $99.64 \%$ and $0.36 \%$ of this, respectively[22]. As shown in Figure 3, the administrative region of Fujin is located on the Sanjiang Plain, in the northeast of Heilongjiang; its total area is $8,224 \mathrm{~km}^{2}$, with a north-south span of $92 \mathrm{~km}$ and west-east span of $180 \mathrm{~km}$. Within the territory of Fujin, the main population centres are 11 towns and one farm (Jiansanjiang farm, including three substations), and the populations of its 508 villages are relatively low[23]. Fujin is a typical agricultural village-town system on a plain, and possesses both high- and low-density regions of village and town distributions. It therefore conforms to all the assumptions required for the biomass CHP plant network model. Therefore, Fujin was chosen for this case study, and the results should provide conclusions that are relevant beyond the case study.

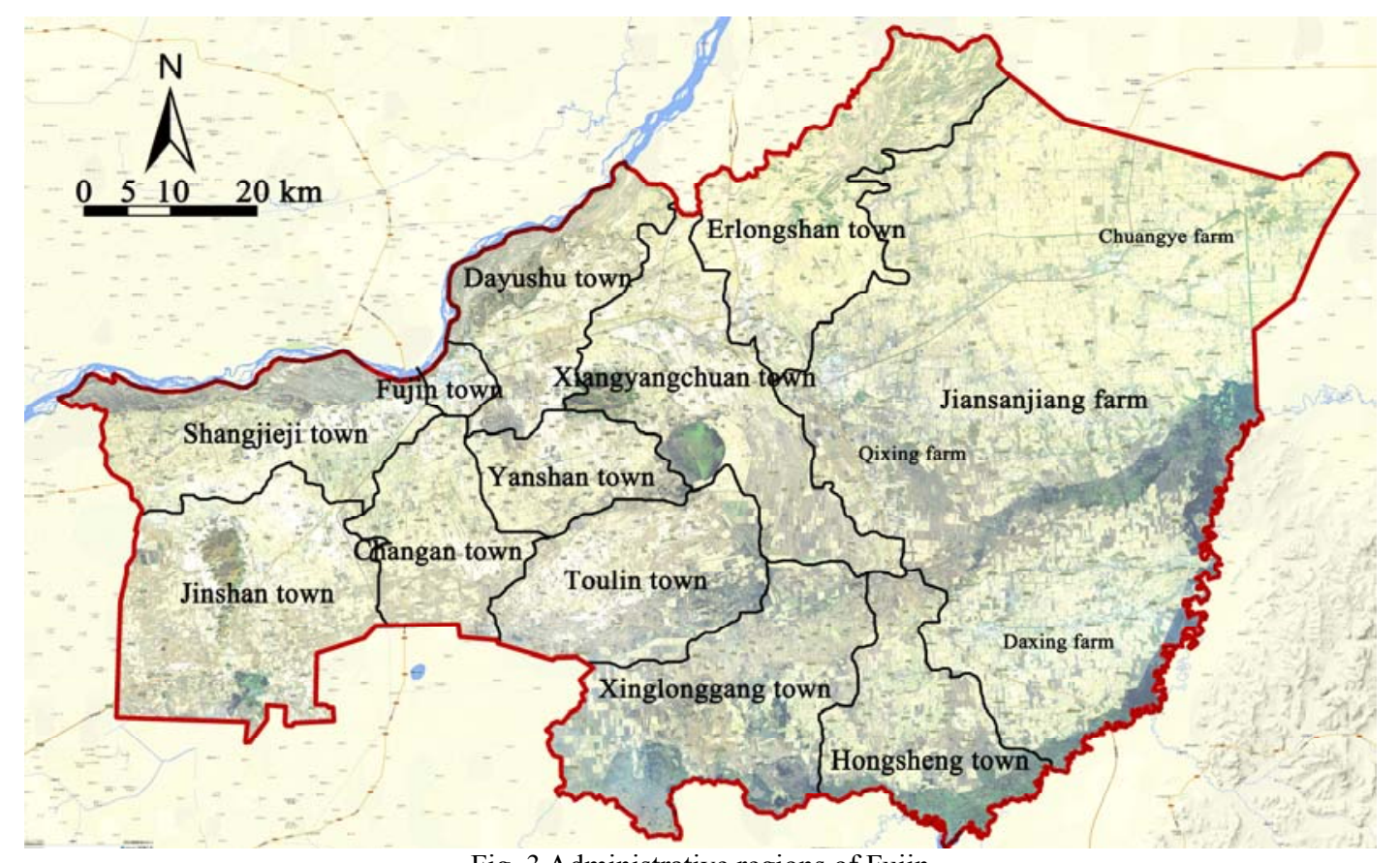

Fig. 3 Administrative regions of Fujin 
Heilongjiang province is the most important area for food production in China, so it is difficult to develop specialist energy crops; however, large quantities of crop residue are sufficient to develop biomass energy. Owing to the high latitude, winter heating consumes a lot of energy. If biomass CHP plants could be widely developed to cover the majority of towns and villages, then non-renewable energy requirements for winter heating would be almost non-existent. Furthermore, surplus biomass energy would be available in non-heating season, so it would be economical to build enough biomass fuel production factories for energy storage and peak shaving. Considering realistic operating conditions, additional RES should be utilized alongside biomass CHP plants to optimize the energy consumption structure of Fujin. The high latitude of Heilongjiang $\left(43^{\circ} 25^{\prime} \mathrm{N}\right.$ to $53^{\circ} 33^{\prime} \mathrm{N}$ ) makes solar energy utilisation efficiency very low, so wind power generation represents an alternative energy source. According to official statistics[22], wind power has been widely developed in Heilongjiang in recent years, accounting for $1 \%$ of the total energy consumption structure. Owing to the extreme shortage of construction land, most wind farms are built in the mountains, and the resulting long-distance transmission losses mean that the power generation costs are very high. This weakness indicates that the potential of wind energy as a supplement to biomass energy in village-town systems is limited.

Assuming that the heating network follows paved roads (to save construction costs), ArcGIS software was used to perform a network analysis of the road network in Fujin to generate a partition analysis of the heat transmission threshold, as shown in Figure 4. In Figure 4, the range of the heat transmission threshold is analysed according to the theoretical model. Fujin is divided into multiple regions, with sizes such as $0-1 \mathrm{~km}, 1-2 \mathrm{~km}$, and 2-3 km, which represent the various heat pipeline distances to villages or towns along roads, i.e. the heat transmission thresholds are equal to 1,2, and $3 \mathrm{~km}$ (range: $0-10 \mathrm{~km}$ ) in these regions. All of Fujin's regions can cover the heat transmission threshold range $(6-10 \mathrm{~km})$. Relatively dark colours represent the relatively low heat transmission loss when a biomass CHP plant is built in that region, as well as relatively low heat transmission thresholds.

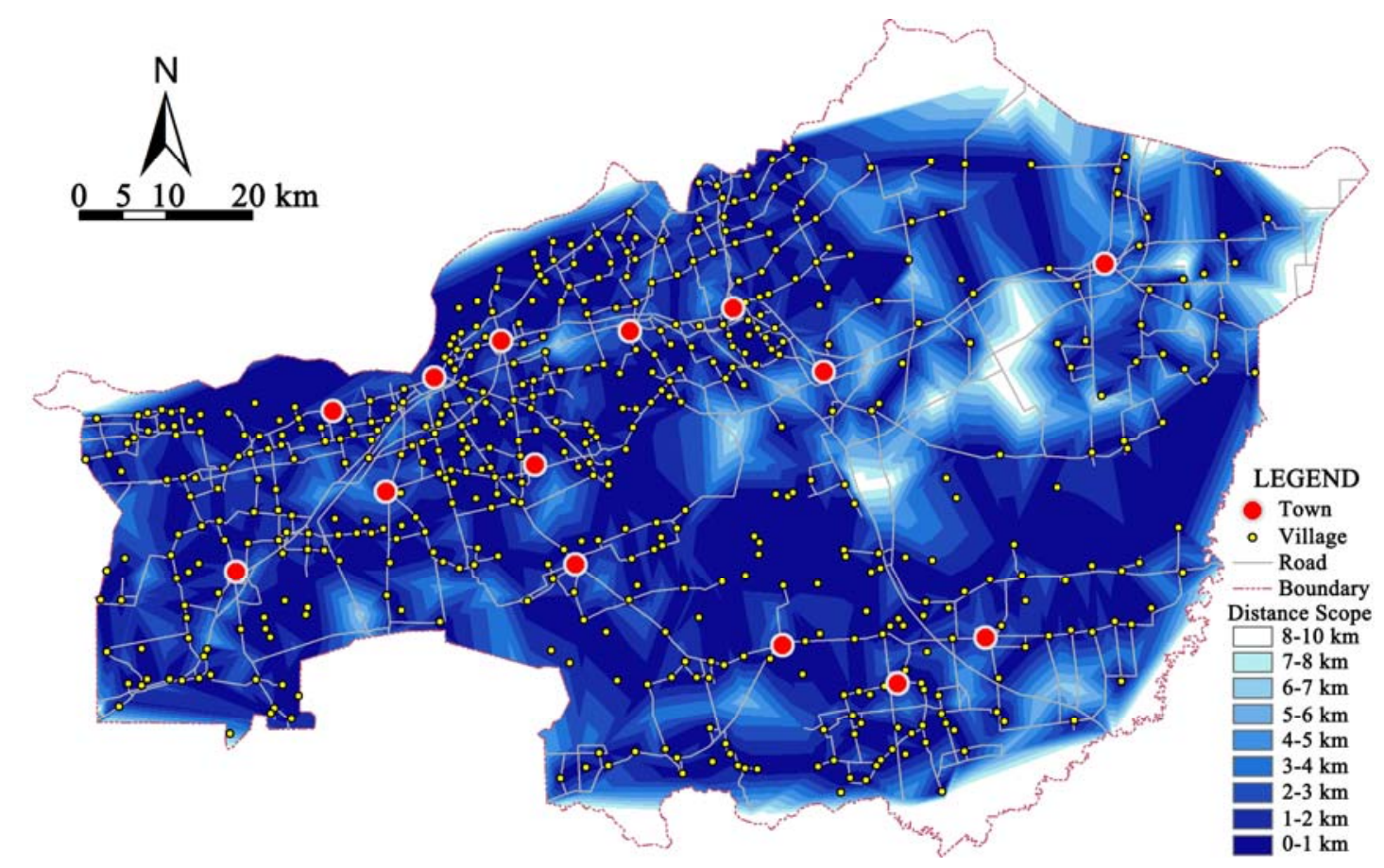

Fig. 4 Partition analysis of heat transmission thresholds in Fujin

Although the distribution densities and populations of villages and towns differ when different cases are chosen, our analysis method nevertheless functioned well. The generated partition analysis of the heat transmission threshold provides a basis for subsequent multi-scheme data comparisons; that is, the heat transmission threshold analysis presented above could be applied to 
other village-town systems besides Fujin.

\section{Results: relevant factors and multi-scheme comparison for heat utilisation efficiency}

In addition to the partition analysis of the heat transmission threshold, other factors relating to heat utilisation efficiency must be considered, including heat demand distribution, heat output efficiency, and heat transmission loss 24$]$. Different heat transmission thresholds were set, generating several biomass CHP plant network planning schemes with different distribution densities. The heat utilisation efficiency of each was then calculated based on the analysis of these three factors. Through a comparison of the heat utilisation efficiencies of these different schemes, the optimal planning scheme for the biomass CHP plant network with the highest heat utilisation efficiency was selected, and the optimal value of the heat transmission threshold was determined.

\subsection{Heat demand distribution}

Essentially, research on the heat demand distribution involves analysing and confirming the quantity and gross power of biomass CHP plants. Therefore, these two indices were calculated based on the local population and the per capita energy consumption index. An ArcGIS network overlay analysis was employed for the populations, locations, and road networks of all villages and towns in the study area, and the results revealed the population distribution in Fujin as shown in Figure 5. This figure provides the population distribution data for all regions in Fujin, allowing the gross power of all the proposed biomass CHP plants based on the per-capita energy consumption index $(562 \mathrm{kWh} / \mathrm{y}[23])$ to be determined. In addition, these results provide accurate quantified data for generating a biomass CHP plant network planning scheme, and for further comparisons with multi-scheme data.

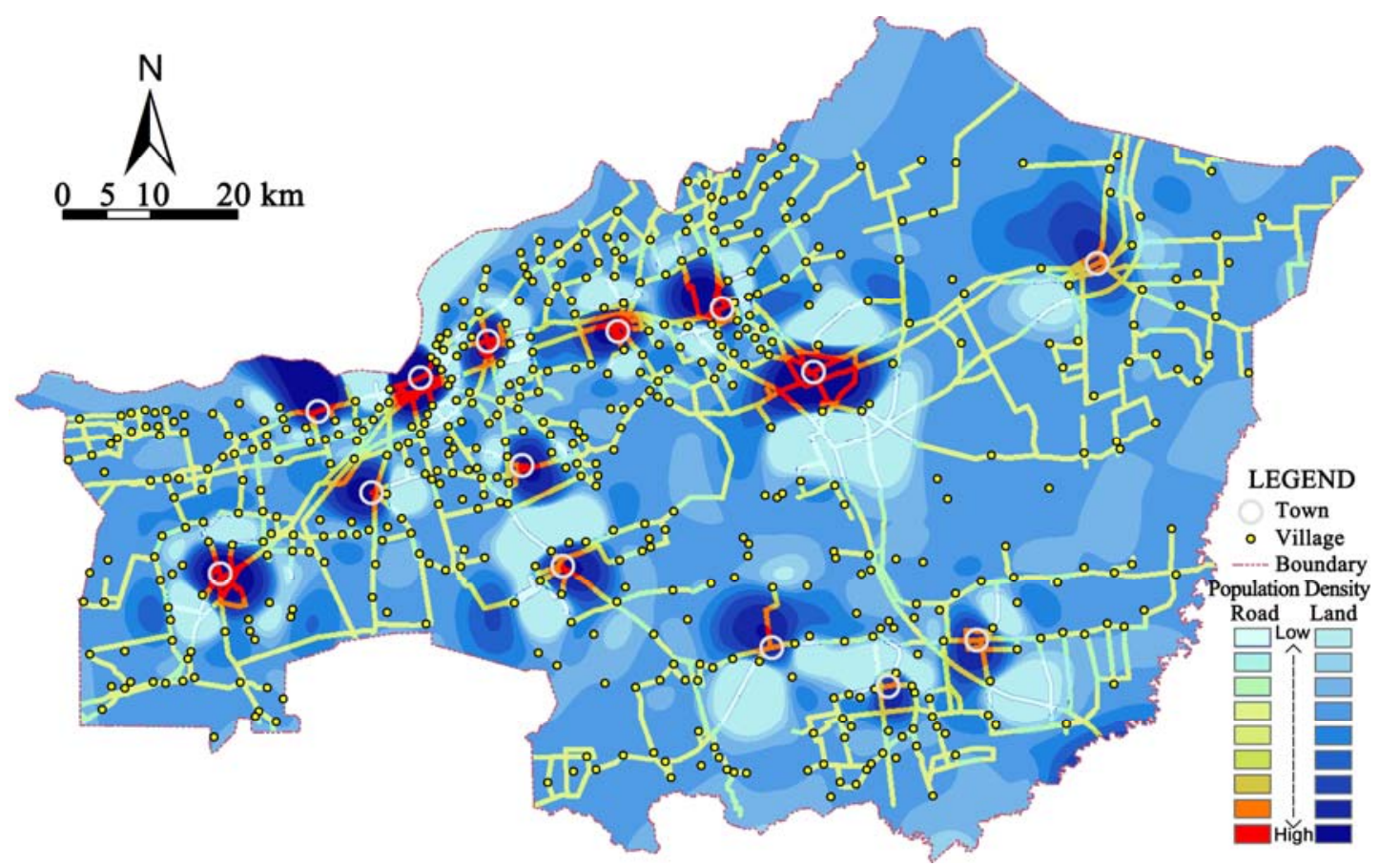

Fig. 5 Distribution density of the population in Fujin

\subsection{Heat output efficiency}

The heat output efficiency of a biomass CHP plant is given by the product of its energy conversion efficiency and heat-electricity ratio (specifically, the ratio of heat energy to electricity generated by the same power plant); therefore, these two indices must first be evaluated. According to research by Dornburg et al.[10] and Amit et al.[12], when the energy conversion efficiency of a biomass CHP plant increases, its gross power also increases (Figure 6), but this increasing trend 
slows when the gross power of the plant reaches $2.5 \mathrm{MWh}$. According to research by Dai et al.[25] and Liu et al.[26] on the generator units of biomass CHP plants, when the gross power of a biomass CHP plant increases, its heat-electricity ratio decreases (Figure 7); however, this trend slows when the gross power of the biomass CHP plant reaches 5 MWh.

Given these two trends, the relationship between the gross power and the heat output efficiency of biomass CHP plants can be determined as shown in Figure 8. The heat output efficiency of a biomass CHP plant reaches a peak value when the gross power of the plant equals 2.5 MWh. The heat output efficiency initially rises rapidly and then slowly declines. This variable function cannot prove that small biomass CHP plants are more economical than large ones; however, it can demonstrate that when the plant is small, the heat output efficiency is high and the electricity output efficiency is low. In contrast, when the plant is large, the heat output efficiency is low and the electricity output efficiency is high.

\subsection{Heat transmission loss}

A correlation analysis of the statistical results for the heat loss ratio of the heating network in Heilongiiang Province showed that the former was directly proportional to the heat transmission distance (Table 1). When the heat transmission distances were 6,8 , and $10 \mathrm{~km}$, the heat loss ratios of the network were $1.01 \%, 1.35 \%$, and $1.69 \%$, respectively. Using these results, the respective heat transmission losses were calculated using a multi-scheme comparison.

Table 1 Heat transmission distance and heat loss

\begin{tabular}{ccc}
\hline Heat transmission distance $\mathbf{( k m )}$ & Heat loss ratio (\%) & Cost conversion (10,000 RMB) \\
\hline 2 & 0.34 & 58.60 \\
4 & 0.68 & 117.19 \\
6 & 1.01 & 175.79 \\
8 & 1.35 & 234.38 \\
10 & 1.69 & 292.98 \\
\hline
\end{tabular}

\subsection{Optimal value for the heat transmission threshold}

The above analysis produced results for heat demand distribution, heat output efficiency, and heat transmission loss, but the heat transmission threshold cannot be predicted directly using a comprehensive analysis that incorporates all three factors simultaneously. Therefore, based on the discussion of the range of heat transmission threshold values in section 2.1, and the partition analysis results for the heat transmission threshold shown in Figure 4, the heat transmission 
threshold was set to three typical values: 6,8 , and $10 \mathrm{~km}(6$ and $10 \mathrm{~km}$ are the minimum and maximum values, respectively; $8 \mathrm{~km}$ is the median value). ArcGIS software was used to simulate and generate three planning schemes for the biomass CHP plant network (Figure 9), and the optimal scheme with the highest heat utilisation efficiency was investigated. To calculate the heat utilisation efficiency for each biomass CHP plant network planning scheme, the following formulae were used:

$$
\begin{aligned}
& H_{g}=\frac{F L \sum_{i=1}^{n} G_{i} H_{i}}{\sum_{i=1}^{n} G_{i} H_{i}} \\
& G_{i}=P_{i} E \\
& H_{i}=T_{i} R_{i}
\end{aligned}
$$

where $H_{g}$ is the heat utilisation efficiency of the biomass CHP plant network, $F$ is the load ratio of the biomass CHP plant, $L$ is the heat loss ratio of the heating network, $G_{i}$ is the gross power of the biomass CHP plant ( $i$ $=1,2,3 \ldots n), H_{i}$ is the heat output efficiency of the plant $(i=1,2,3 \ldots n), P_{i}$ is the population in the plant service area $(i=1$, $2,3 \ldots n), E$ is the annual per-capita energy consumption, $T_{i}$ is the energy conversion efficiency of the plant $(i=1,2,3 \ldots n)$, and $R_{i}$ is the heat-electricity ratio of the plant ( $i$ $=1,2,3 \ldots n)$.

In these formulae, $F$ was set to $80 \%$, based on the average electricity consumption from statistical data for Heilongjiang Province, and $L$ was determined based on the data listed in Table 1 . In addition, $G_{i}$ was calculated according to $P_{i}$ and $E\left(562 \mathrm{kWh} / \mathrm{y}\right.$ in 2016, according to Fujin statistical yearbook (2016)[23]). $H_{i}$ was calculated from the product of $T_{i}$ (Figure 6) and $R_{i}$ (Figure 7). Finally, the three planning schemes were compared with regard to the different heat transmission thresholds, revealing the relationships between the various indices, as shown in Figure 10.

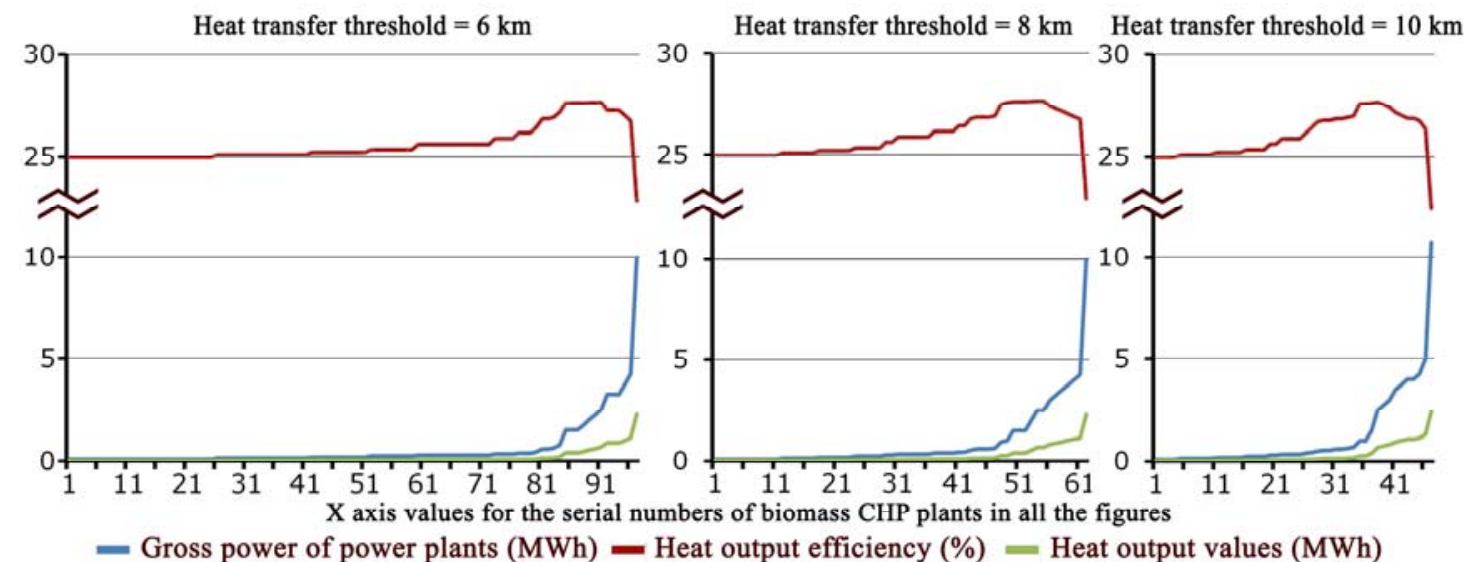

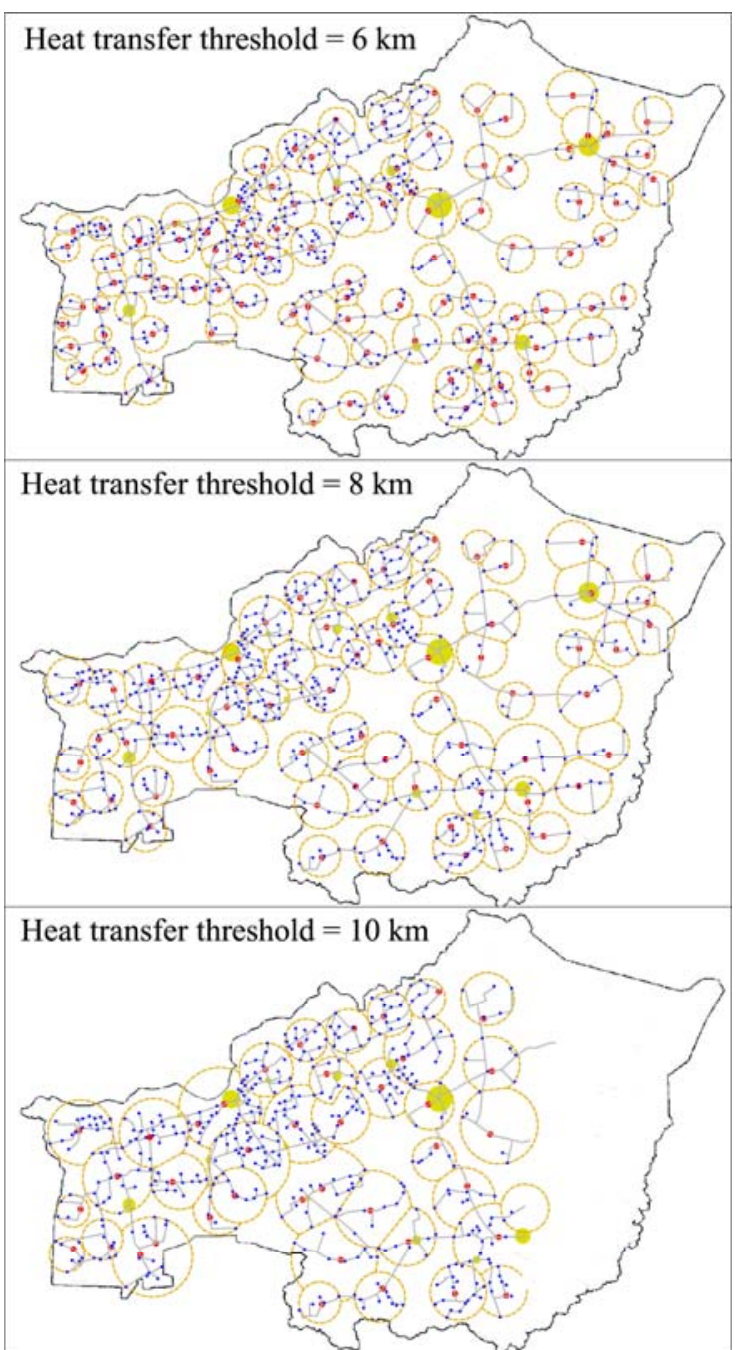

Town •Village • Biomass CHP plants Service radius of biomass $\mathrm{CHP}$ plants Heat pipe network

Fig. 9 Biomass CHP plant network planning, using different heat transmission thresholds 
Fig. 10 Indices of biomass CHP plants with different heat transmission thresholds

As shown in Figure 10, at least 97, 62, and 47 biomass CHP plants were needed in Fujin when the heat transmission threshold was equal to 6,8 , and $10 \mathrm{~km}$, respectively. Since the biomass CHP plants are ordered according to their gross power in each respective scheme, it is clear that the number of large biomass CHP plants is very similar among the three schemes, whereas the differences in the number of small plants are huge. Comparison of the data for these three planning schemes reveals that when the heat transmission threshold is low, the distribution density of biomass CHP plants is high and there are a greater number of small plants, whereas when the heat transmission threshold is high, the distribution density of plants is low and there are more large plants.

The results calculated according to formulae (1), (2), and (3), after determining the related indices, show that the heat utilisation efficiencies of the biomass CHP plant network planning schemes were $24.92 \%, 24.98 \%$, and $24.71 \%$ when the heat transmission thresholds were 6,8 , and $10 \mathrm{~km}$, respectively. The comparison of the three schemes shows that the heat utilisation efficiency is highest when the heat transmission threshold is equal to $8 \mathrm{~km}$; therefore, this is the optimal value of $T$. Using this value, the biomass CHP plant network planning scheme generated using ArcGIS software achieves the highest heat utilisation efficiency.

This study constructed a model of a biomass CHP plant network that contrasts with traditional design methods used in village-town system planning (Figures 1 and 2). ArcGIS software was used to a perform a partition analysis of the heat transmission threshold (Figure 4). The heat demand distribution was calculated according to local population distributions (Figure 5). The heat output efficiency was calculated from the gross power, heat conversion efficiency, and heat-electricity ratio (Figures 6, 7, and 8). The calculation method for heat transmission loss is given in Table 1. ArcGIS software was used to simulate and generate three planning schemes for the biomass CHP plant network by setting the heat transmission threshold to 6,8 , and $10 \mathrm{~km}$ (Figure 9). Finally, a multi-scheme data comparison method was employed, leading to the conclusions set out in section 4 .

\section{Conclusions}

It is feasible to obtain an optimal scheme for a biomass CHP plant network using GIS tools to analyse the distribution and population density of village-town systems; from the perspective of village-town system planning, this optimal scheme can improve heat utilisation efficiency and reduce energy waste.

1. A comparison the gross power and numbers of biomass CHP plants among the three planning schemes for the biomass CHP plant network showed that when the heat transmission threshold was low, the distribution density of the biomass CHP plant network was relatively high and the plants tended to be relatively small-scale. In contrast, a higher heat transmission threshold corresponded to a relatively low network distribution density and a relatively large-scale biomass CHP plants.

2. A comparison of heat utilisation efficiency indices among the three planning schemes for the biomass CHP plant network showed that when the heat transmission threshold was $8 \mathrm{~km}$, the planning scheme generated via GIS tools achieved the highest heat utilisation efficiency using the lowest density arrangement.

Based on theoretical deduction and simulation analysis, it is clear that the outstanding advantages of the biomass CHP plant network model are its high practicability and low implementation cost; it is more economical to acquire population distribution data from local governments than to buy expensive high-resolution VR data or gather data from field surveys. The theoretical model and GIS analysis methods presented here can easily be applied to other village-town systems to optimize the heat utilisation efficiency of biomass CHP plant networks. 


\section{References:}

[1] Hepbasli A. A key review on exergetic analysis and assessment of renewable energy resources for a sustainable future[J]. Renewable Sustainable Energy Reviews, 2008, 12(3): 593-661.

[2] Tasneem A., Abbasi S.A. Biomass energy and the environmental impacts associated with its production and utilization[J]. Renewable and Sustainable Energy Reviews, 2010, 14(4): 919-937

[3] Scarlat N., Dallemand J., Monforti-Ferrario F., et al. Renewable energy policy framework and bioenergy contribution in the European Union - An overview from National Renewable Energy Action Plans and Progress Reports[J]. Renewable Sustainable Energy Reviews, 2015, 51(11): 969-985

[4] Peter M. Energy production from biomass (part 2): conversion technologies[J]. Bioresource Technology, 2002, 83(1) :47-54.

[5] Guo M., Song W., Buhain. Bioenergy and biofuels: History, status, and perspective[J]. Renewable Sustainable Energy Reviews, 2015, 46(6): 218-235.

[6] Scarlat N., Dallemand J., Monforti-Ferrario F., et al. The role of biomass and bioenergy in a future bioeconomy: Policies and facts[J]. Environmental Development, 2015, 15(7): 3-34.

[7] Göran F. Biomass energy transport Analysis of bioenergy transport chains using life cycle inventory method[J]. Biomass and Bioenergy, 2000, 19(1): 17-30

[8] Thomas B., Markus B., Sabine G., et al. "Energy landscapes": Meeting energy demands and human aspirations[J]. Biomass and bioenergy 2013:55(8):3-16.

[9] Xun S., Andrew E., Xia L., et al. Using spatial information technologies to select sites for biomass power plants: A case study in Guangdong Province, China[J]. Biomass and bioenergy, 2008, 32(1): 35-43.

[10] Dornburg V., Faaij APC. Efficiency and economy of wood-fired biomass energy systems in relation to scale regarding heat and power generation using combustion and gasification technologies[J]. Biomass and Bioenergy, 2001, 21(2): 91-108

[11] Lu C., Xi L. Economic analysis of heating network's heating distance[J]. China science and technology information, 2011,18(11): 223-224

[12] Amit K., Jay B., Peter C. Biomass power cost and optimal plant size in western Canada[J]. Biomass and Bioenergy, 2003, 24(6): 445-464.

[13] Biberacher M, Gadocha S, Zocher D. GIS based model to optimize possible self sustaining regions in the context of renewable energy supply[C]. Proceedings of the iEMSs fourth biennial meeting: international congress on environmental modelling and software. Spain-Barcelona: International Environmental Modelling and Software Society, 2008: 1306-1313.

[14] Biberacher M, Gadocha S. GIS based model to optimize the utilization of renewable energy carriers and related energy flows[C]. 18th world IMACS congress and MODSIM09 International congress on modelling and simulation. Australia-Canberra: Modelling and Simulation Society of Australia and New Zealand and International Association for Mathematics and Computers in Simulation, 2009: 1915-1921.

[15] Blaschke T, Biberacher M, Gadocha S, et al. Virtual power plants: spatial energy models in times of climate change[C]. Proceeding of digital earth summit on geoinformatics. Germany-Heidelberg: Wichmann-Verlag, 2008: 61-66.

[16] Prinz T, Biberacher M, Gadocha S, et al. Potential of renewable energy with global efforts[C]. Proceeding of Austrian conference on spatial planning: energy and spatial development. Germany-Westman press: 2009:1-131.

[17] Moser P, Kucharczak L, Hoppenbrock C. How to achieve renewable energy regions and advance sustainable development?[C]. 100 percent renewable energy autonomy in action. United Kingdom-London: Earthscan, 2009: 173-187.

[18] Zhang Y., Tian G., Sun Y., et al. Comparison of Network Heat Loss Rate between Steam Centralized Heat-supply and Hot Water Centralized Heat-supply[J]. Gas \& Heat. 2008, 28(5): 13-16

[19] Wang W., Xu J., Yang T., et al. Urban transportation planning theory and application [M]. Nanjing: Southeast university press, 1998

[20] Ma K., Zhang Y. Spatial Planning Pattern of Biomass Energy Developing Network in Heilongjiang Province's Village-Town System [J]. Urban Development Studies, 2016, 23(6): $15-18$

[21] National Bureau of Statistics of the People's Republic of China, China Statistical Yearbook 
(2016). 2016: 261

[22] Heilongjiang's bureau of statistics. Heilongjiang's statistical yearbook (2016)[M]. Beijing: China Statistics Press, 2016: 119-209

[23] Fujin bureau of statistics. Fujin statistical yearbook (2016)[J]. 2016: 26

[24] Zhang Y., Zhao T., Ma K. Improving Spatial Planning under Perspective of Energy Landscape: Research on Development Strategy of Biomass Energy in Heilongjiang Province [J]. Urban Development Studies, 2014, 21(9): 1-4

[25] Dai J., Liu G., Xu T., et al. Research on heat-electricity ratio's affecting factors of heating unit[J]. Huadian Technology, 2013, 35(12): 7-11

[26] Liu L., Han B., Zhang R. Heating's economic analysis for CHP units based on heat-electricity ratio[J]. District heating, 2010, 36(1): 64-66 